\title{
Responding to Hate Crime: Escalating Problems, Continued Failings ${ }^{1}$
}

\begin{abstract}
The need for fresh responses to hate crime has become all the more apparent at a time when numbers of incidents have risen to record levels, both within the UK and beyond. Despite progress within the domains of scholarship and policy, these escalating levels of hate crime and the associated increase in tensions, scapegoating and targeted hostility that accompanies such spikes - casts doubt over the effectiveness of existing measures and their capacity to address the needs of hate crime victims. This article draws from extensive fieldwork conducted with more than 2,000 victims of hate crime to illustrate failings in relation to dismantling barriers to reporting, prioritising meaningful engagement with diverse communities and delivering effective criminal justice interventions. It highlights how these failings can exacerbate the sense of distress felt by victims from a diverse range of backgrounds and communities, and calls for urgent action to plug the ever-widening chasm between state-level narratives and victims' lived realities.
\end{abstract}

Key words: hate crime; victims; under-reporting; diversity; criminal justice policy

Word count: 8,647

Author details: Professor Neil Chakraborti (Department of Criminology, University of Leicester, 154 Upper New Walk, Leicester, LE1 7QA); nac5@le.ac.uk; 01162525706

Author biography: Neil Chakraborti is Professor of Criminology, Head of the Department of Criminology and Director of the Centre for Hate Studies at the University of Leicester. 


\section{Introduction}

Hate crime has become increasingly relevant to criminology in recent times. The term has been used within the domains of policy and scholarship as a way of distinguishing forms of violence and microaggressions directed towards people on the basis of their identity, 'difference' or perceived vulnerability. It has been used to promote awareness, action and shared understanding amongst a range of different actors including law-makers, non-governmental organisations, activists and professionals within and beyond the criminal justice sector. And it has been used to facilitate increased prioritisation across disciplines, across communities and across borders.

The need for prioritisation has become all the more urgent in the context of rising levels of hate incidents across many parts of the world. Within the UK, the EU referendum result of June 2016 was a catalyst for an upsurge in reports of targeted violence. More than 14,000 hate crimes were recorded by police forces in England and Wales between July and September 2016, with three-quarters of forces reporting record levels of hate crime during that period (BBC News, 2017a). Those figures revealed an increase in incidents across almost every police force within England and Wales, both year on year and when comparing the three months either side of the referendum, with ten force areas recording a rise of more than 50\%. Equally worrying spikes were seen within the US following a build-up of tensions during and after the 2016 presidential campaign (Southern Poverty Law Centre, 2016) and across Europe with populist political parties in countries such as France, Denmark, Germany, Austria, Hungary and the Netherlands exploiting anti-immigrant sentiment, fuelling the scapegoating of particular minority groups and stoking up widely-held anxieties (BBC News, 2017b; Dearden, 2017).

This growth of hate incidents paint a worrying picture, not least because it is rooted within a wider, structural process whereby expressions of hate, prejudice and hostility are used to marginalise 'difference' and to sustain hegemonic boundaries. An increasingly extensive body of literature has shown that attacks against the 'other' can feed off economic instability, political scaremongering and media stereotyping to the point where violence becomes a mechanism used to reinforce power dynamics between dominant and subordinate groups and to create cultures of fear within alien communities (see, inter alia, Chakraborti and Garland, 2012; Perry, 2001). Research has also shown how 'trigger' events of local, national and international significance can influence the prevalence and severity of hate incidents within cyberspace and the physical world, thereby heightening the vulnerability of many groups and communities at a time when 'other' identities are under greater scrutiny than perhaps ever before (Awan and Zempi, 2017; Chakraborti and Garland, 2015). 
Without question, some significant progress has been made in relation to improving levels of support for victims ${ }^{2}$ of hate crime, and this will be considered in due course. However, this article will show that these developments have been only partially effective in addressing victims' needs and lived experiences, and that the damage caused by hate crime can often be reinforced - and not alleviated - by the continued failures of policy-makers, practitioners and scholars to respond and engage effectively. Drawing from a series of recent studies led by the author which elicited the views of more than 2,000 victims of hate crime, this article identifies three areas of failure - namely, in relation to dismantling barriers to reporting, prioritising meaningful engagement with diverse communities and delivering meaningful criminal justice interventions - and the ways in which they can exacerbate the sense of distress felt by victims from a diverse range of backgrounds and communities. Before turning to these points, the article first considers the value and limitations of recent developments in policy and scholarship with regard to addressing the problems associated with hate crime.

\section{Questioning the relationship between hate crime policy, scholarship and lived experiences}

'Hate' is an emotive, elastic and conceptually ambiguous label, and this has important implications for the offences which are classified as forms of hate crime and for the groups of victims who are offered protection under its umbrella framework (Chakraborti and Garland, 2015). Many different definitions can be found within the wider literature but almost all are consistent in referring to a broader range of factors than hate alone to describe the motivation that lies behind the commission of a hate crime (see, inter alia, Chakraborti, Garland and Hardy, 2014; Hall, 2013; Chakraborti and Garland, 2012; Perry, 2001). In particular, terms such as 'targeted hostility', 'prejudice' and 'bias' have all been used interchangeably by criminologists as a way of highlighting that the presence of 'hate' itself is not central to the commission of a hate crime.

These academic contributions have helped to illustrate the complexities associated with hate crime by highlighting the relationship between structural hierarchies, institutionalised prejudices and acts of hate. They have identified the relevance of power dynamics within modern societies and that expressions of violence are qualitatively different when motivated by bigotry and directed towards already disempowered and marginalised populations. They have shown that some hate crime victims can be targeted not exclusively because of their membership of a particular identity group but also because they are seen as being especially vulnerable or 'different' in the eyes of the perpetrator on the basis of other aspects of self or through the interplay of multiple identity characteristics, situational factors and prevailing social and economic conditions within different micro-spaces. These academic contributions 
have also highlighted the multiple layers of harm associated with hate offences which commonly include excessive physical violence and brutality, emotional damage, psychological scars and the escalation of social tensions (see also Iganski and Lagou, 2015; ODIHR, 2009).

Some laudable attempts to develop a common understanding that can generate workable responses to hate crime have emerged outside of the academic domain. Guidelines issued by the College of Policing, the professional body responsible for setting standards in professional development across English and Welsh police forces, require the police to record and investigate any hate incident, whether a prima facie 'crime' or not, if it is perceived by the victim or any other person (such as a witness, a family member or a carer) as being motivated by hostility or prejudice towards any one of five monitored strands of identity: namely, disability, race, religion, sexual orientation and transgender status. Most hate crime interventions within the UK are based around these five strands, although the College of Policing guidance encourages police forces to record other forms of targeted hostility as hate crime beyond the five strands if there are valid reasons for doing so. This has enabled a number of individual forces to monitor other offences - including violence against alternative subcultures and sex workers, and more recently misogynistic harassment - as additional strands of hate crime within their local areas (Mason-Bish, 2016; Garland and Hodkinson, 2015; Campbell, 2014).

The principles underpinning these developments within the domains of policy and scholarship have been supported by successive UK Government Action Plans (Home Office, 2012; 2016) which are designed to reinforce its commitment to tackling hate crime. The most recent of these, Action Against Hate, was published in the wake of the post-Brexit rise in recorded hate incidents across many parts of England and Wales, and refers to the importance of protecting 'the shared values that underpin the British way of life' (Home Office, 2016: 5) through a series of actions and priority areas which seek to identify best practice across all strands of hate crime. However, while the Action Plan sets commendable goals in relation to prevention, reduction and support for victims, it fails to specify how these goals will be achieved and evaluated or how the empirical evidence produced by academic research will be used to promote best practice (Walters and Brown, 2016). As such, and often despite the very best of intentions, the value of empirical research and progressive policy can be diminished through a lack of synergy between the two domains.

A polarised approach to hate crime scholarship and policy formation can reinforce the perception that academic theorising is often too detached from the everyday realities confronting those who deal with hate crime cases in the 'real world' (Giannasi, 2015). If academic debate is to shape policy and 'real-life' responses to hate crime victims, definitions need to be constructed and presented in ways that have meaning to people who are affected by, 
and who are responsible for responding to hate crime. Equally, if the value of academic theorising becomes more evident when it reaches beyond its own echo chamber to connect with hate crime responses and experiences, then the value of criminal justice interventions is similarly enriched when such interventions are grounded in scholarly evidence and relevant input from other sectors. However, in reality these kinds of holistic interventions may not exist where community and third sector organisations lack the capacity to shape policy makers' opinions about the relevance or prevalence of hate crime; or where the influence of academic work may be hampered by scholars having conducted limited or no research in particular contexts; and where such work is seen as peripheral to policy formation and frontline work with victims (Chakraborti, 2015a; Perry, 2014).

Potentially, then, conceptual ideas which do not connect with 'real-world' requirements, and policy responses which are not rooted in empirical evidence, can create problems for the sustainability of hate crime interventions. For the most part these kinds of problems will stem from a lack of clear thinking, a perceived shortage of time or a desire to find 'quick-fix' solutions, as opposed to any sense of deliberate neglect or oversight. However, their impact upon hate crime victims' perceptions and lived realities can be significant. This article seeks to explore those perceptions and lived realities by drawing from a series of recent studies conducted with a diverse range of research participants. Following a brief outline of the methodologies employed within these studies, the article presents their key findings which illustrate a set of perceived failings, challenges and barriers to justice which exacerbate the harms associated with hate crimes.

\section{Methodology}

The findings that follow in the next section are taken from a series of studies led by the author and completed over the past five years. Each of these four studies was commissioned by a different funding body ${ }^{3}$ but they shared the common goals of seeking to uncover lived experiences of hate crime, to understand the physical and emotional harms suffered by victims and their families, and to identify ways of improving the quality of support offered to victims. As such, relevant analysis from each study is presented collectively within this article in order to identify common failings in responses to hate crime as perceived by victims from a diverse range of backgrounds.

The first of these studies - the Leicester Hate Crime Project - was a two-year piece of research funded by the Economic and Social Research Council which ran from 2012-2014. In order to facilitate access to as large and as diverse a sample as possible, the research team spent prolonged periods of time engaging with people in public spaces and buildings across the city 
of Leicester, including international supermarkets, cafes and restaurants, charity shops, community and neighbourhood centres, health centres, places of worship, pubs and clubs, taxi ranks, shelters and drug and alcohol services. This enabled the team to raise awareness of the study amongst groups and communities who are typically disconnected from research, activism and policy-making and to develop the necessary levels of rapport and trust required for sensitive research of this nature. A total of 1,106 victims of hate crime aged 16 and over shared their experiences and perceptions through completion of an online or hard-copy survey which had been translated into eight different languages ${ }^{4}$, and 374 victims took part in in-depth, semi structured interviews.

The profile of research participants within the Leicester Hate Crime Project was diverse in terms of age, gender identity, ethnicity, religion, sexual orientation and disability, and included sizeable numbers of participants from 'hidden', less familiar or emerging communities including, for instance, people victimised because of their 'different' modes of dress, appearance or lifestyle $(n=376)$; people with learning disabilities and/ or mental ill-health $(\mathrm{n}=229)$; members of recently arrived migrant groups such as the Roma, Polish, Somalian, Congolese and Iranian communities $(n=197)$; members of the trans community $(n=44)$; and homeless people ( $\mathrm{n}=15)$ (see Chakraborti, Garland and Hardy (2014) for further details). As was found within each of the studies described below, the generic labels used to describe victims' identity groups masked a considerable degree of diversity within those groups, and this itself has significant implications for the effectiveness of support services. For instance, the 271 victims who had been targeted on the basis of their disabilities suffered from a range of physical and/or learning disabilities and mental health conditions, including anxiety disorders, autism, cerebral palsy, depression, Down's syndrome, impaired speech, memory loss, multiple sclerosis, schizophrenia and assorted other learning, mobility and movement impairments.

The second study was conducted over a four-month period in 2015 and was funded by the Equality and Human Rights Commission. This study focused specifically on the experiences of Lesbian, Gay, Bisexual and Transgender (LGBT) victims of hate crime based in Leicester and Leicestershire, and a similarly rigorous process of engagement was used whereby the research team spent prolonged periods of time within a wide range of known LGBT venues and community hubs, including cafes, bars, community groups, forums and other informal networks, in order to build connections with a diverse sample of LGBT people within their familiar environments and social spaces. The team used in-depth face-to-face qualitative interviews to explore experiences and expectations with a total of 50 people who identified as LGB and/or T, of whom 50\% $(n=25)$ were women, $50 \%(n=25)$ were men and $10 \%(n=5)$ described themselves as transgender. Again, the sample was made up of a diverse profile of ages, ethnicities and socio-economic backgrounds and included victims who had a range of 
overlapping identity characteristics, such as being gay and Muslim, or being trans and physically disabled (see Chakraborti and Hardy, 2015).

The third study was commissioned by the Office for the Police and Crime Commissioner (OPCC) in Hertfordshire and took place over a four-month timeframe in 2016. The OPPC and Hertfordshire County Council facilitated access to key gatekeepers, points of access and service providers and users within the county, and this support - allied with the grassroots engagement and social media strategies deployed to raise awareness of the research - enabled the research team to capture the perceptions and experiences of 1,652 actual and at risk victims of hate crime through responses to online and hard copy questionnaire surveys $(n=1,604)$ and in-depth interviews $(n=81)^{5}$. This approach to sampling and choice of method was mirrored within the final study referred to within this article, which was conducted over a six-month timeframe in 2017 on behalf of the Office for the Police and Crime Commissioner (OPCC) in the West Midlands. A total of 373 people took part in the West Midlands-based study through participation in an online or hard copy survey $(n=360)$ or through an interview $(n=45)$. Further details about the methodologies and demographic breakdowns of the Hertfordshire- and West Midlands-based studies can be found elsewhere (Hardy and Chakraborti; 2017a; 2016), but it is important to note that, as with the Leicester Hate Crime Project, research participants within both of these studies came from a diverse range of backgrounds in terms of age, disability status, ethnicity, gender identity, religion, sexual orientation and socio-economic status, and included victims who had been targeted on the basis of having multiple identity characteristics and on multiple occasions.

\section{Findings}

A series of key themes emerged from each of these studies in relation to the continued failings of existing hate crime responses to meet the needs and expectations of victims. These include a failure to dismantle barriers to reporting; a failure to prioritise meaningful engagement with diverse communities; and a failure to provide meaningful criminal justice interventions for victims. These themes are discussed below, and anonymised verbatim extracts from interviews ${ }^{6}$ and relevant survey data have been used for illustrative purposes to support the arguments presented. Although direct references to the qualitative material have been used sparingly for the sake of brevity, those quotations that have been included are illustrative of concerns raised by all strands of hate crime victims across each study.

\section{A failure to dismantle barriers to reporting}


The police response to hate crime, and those from other organisations within and beyond the criminal justice sector, is contingent on incidents being reported by the victim or any other person present. The importance of reporting in the context of generating effective prioritisation and service delivery is well documented, both within previous academic research on hate crime (Chakraborti and Garland, 2015; Wong and Christman, 2008) and within key sources of policy guidance (College of Policing, 2014; HM Government, 2014; 2012); indeed, the most recent Hate Crime Action Plan issued by the UK Government pledges to 'ensure that everyone has the opportunity and information needed to report hate crime' (point 89) while in its Foreward the Secretary of State for Communities and Local Government states that 'if we report every incident of hate crime, we can drive it from our streets' (2016: 6).

Evidence from the present studies suggest that we have a very long way to go before these words can become a reality. Within the Leicester Hate Crime Project, for example, fewer than one in four survey respondents had reported their experiences of hate crime to the police (24\%; $\mathrm{n}=265$ ) and fewer still had shared their experiences with other organisations who could potentially have offered support such as a teacher (4\%; $n=47)$, Victim Support (3\%; $n=31)$; their local authority $(3 \% ; n=28)$; or a social care worker $(2 \% ; n=20)$. Only $1 \%$ of these respondents had shared their experiences of victimisation with a community support organisation, such as an LGBT, disability or race equality network, while none had ever utilised any of the third-party reporting options available through local libraries or online via True Vision $^{7}$, despite third party reporting schemes (and the use of True Vision as an online information resource and reporting option) being heralded within successive Government Hate Crime Action Plans.

Similar findings emerged from the other studies. For instance, within the Hertfordshire- and West Midlands-based research projects as many as $86 \%(n=1,090)$ and $76 \%(n=240)$ of survey respondents stated that were unlikely to report verbal abuse, with approximately half of all respondents in each study unlikely to report acts of harassment $(51 \%, n=566$; and $49 \%, n=156$, respectively). Collectively these findings present an alarming picture of how often victims of hate crime victims suffer in silence, and how few incidents come to the attention of the police and other agencies. A wide range of factors underpinned victims' reluctance to disclose their experiences, with one of the most common across each study being a perception that reporting would simply be a waste of time, either for the victim (because the police and other partner organisations would fail to grasp the seriousness and prevalence of hate incidents) or for the police (because of a perceived tendency on the part of the police to prioritise other types of offence with easily identifiable perpetrators and more obvious resolutions). As a result, most victims tended to normalise their experiences of repeat harassment and hostility as a routine feature of being 'different', which in turn reinforced their sense of alienation. Equally, many 
victims expressed a sense of trepidation about the prospect of reporting which stemmed from fears about being outed, drawing attention to themselves or retaliatory attacks. This highlights how the process of reporting can in fact exacerbate existing concerns on the part of the victim, rather than provide the necessary levels of reassurance. Although some victims could take a degree of comfort from sharing experiences with friends or family members, the overwhelming majority across all strands of victims and types of incident would have welcomed the opportunity to tell the police or another appropriate 'authority' figure if the barriers to reporting did not feel so insurmountable.

If I went to the police to report every single incident I wouldn't be doing anything else. I would be spending half my day being insulted and humiliated. Then the other half a day I would spend in the police station reporting things.

Transgender woman, aged 40-49

Can you imagine going into the police, saying 'I want to report, he just called me a Black bastard or a Black nigger or a Black cunt and I want to report it'? They'd be laughing.

Black British male, aged 40-49

Will I go to the police and say somebody was being verbally abusive, being racist towards me, chanting these words? Do I expect them to do anything? It's a waste of time. If they cannot deal with Stephen Lawrence in 20 years what chance do I have with verbal abuse? It hurts but it doesn't kill.

Zimbabwean male refugee aged 20-29

The last comment is indicative of a related barrier to reporting shared by many victims within these studies and within other studies of hate crime victimisation (Antjoule, 2016; Spalek, 2006): namely, that victims' previous bad experiences of liaising with the police and other agencies - and the experiences shared by family members, friends and members of their own community - can reinforce a lack of trust and the sense that frontline practitioners fail to show sufficient empathy or kindness to people who find themselves in positions of extreme vulnerability and difficulty. An inability to offer relevant insight, or the perception that practitioners were 'winging it' in terms of their background knowledge of or training in hate crime, was also a common criticism which has been identified in other related contexts too, most notably by Hick et al., (2011) who suggest that the delivery of diversity-themed education 
within schools can often be hampered by an over-reliance upon newly-qualified teachers who can feel out of their depth discussing such issues and ill-equipped to understand cultural differences.

These barriers to reporting are recognised by some frontline practitioners, as acknowledged within each of these studies. Nor are they by any means unique to hate crime reporting (see, for instance, Brooks and Burman, 2017; Walklate, 2007; Radford and Stanko, 1996) for a wider discussion of under-reporting in the context of rape, domestic and sexual violence). However, and when considered in the context of escalating levels of hate incidents, they are illustrative of the challenges facing many victims from different groups and communities who continue to suffer experiences of targeted violence, hostility and repeat harassment in silence. Moreover, perceived weaknesses in third party reporting options cast further doubt over the adequacy of existing responses to victims of hate crime. Although third party reporting centres are designed to overcome some of the initial barriers to reporting by enabling victims to report hate incidents at local venues or online, and not directly to the police, the research studies identified significant problems which compromised the take-up and effectiveness of available reporting options within each area. Perhaps most worryingly, very few of the research participants in any of the studies were familiar with the idea of third party reporting, or with any of the national or local schemes set up to facilitate such reporting. Of those who conveyed at least some awareness of these schemes, most were highly critical of the perceived inaccessibility of third party reporting options, and specifically the inappropriate locations of reporting centres and the potential for digital formats such as websites and mobile phone apps to exclude those who are unfamiliar with or unable to use such technologies.

Clearly under-reporting remains a major challenge in relation to hate crime, and national and regional policy interventions have done little in reality to remove key barriers. The importance of simplifying reporting structures and making them more victim- and witness-friendly cannot be overstated. The vast majority of the victims within these studies who referred to various challenges around reporting had nothing against the principle of reporting per se, and ideally would gladly report incidents in order to access support for the emotional and physical harms experienced and to feel a sense of justice. However, the barriers referred to above - in addition to the cultural and linguistic barriers which particularly affected those from new and emerging communities and those for whom English was not a first language - were significant enough to deter most victims from seeking much-needed help to alleviate their distress. As such, and despite continued reference to improvements in reporting structures within state-level narratives, those structures continue to be framed in a way that fails to acknowledge the needs and concerns of victims. 


\section{A failure to prioritise engagement with diverse communities}

Engagement with diverse, 'hard to reach' communities forms a central theme within much of the policy guidance around hate crime (College of Policing, 2014; HM Government 2014; 2012; ODIHR, 2009). The most recent UK Government Action Plan makes regular references to the importance of working in partnership with communities as a key component of its proposals to tackle hate crime (Home Office, 2016), and this message is reinforced regionally within the hate crime strategies of police forces and local authorities and within Police and Crime Plans put forward by regional OPCCs. However, the evidence from these research studies suggests that community engagement strategies commonly fail to involve those most affected by hate crime. Each study revealed widespread feelings of fear, anger, isolation and disconnection on the part of victims from all backgrounds which had been heightened through an absence of any form of or communication from state or third sector service providers, as acknowledged within these comments from local government employees with direct responsibilities for responding to hate crime.

It seems to have got worse since the restructure. I personally don't feel we're doing very much at all for those victims ... You can't do meaningful engagement.

There are a lot of cutbacks, that's self-evident. And it's further turmoil because we have the issues of Brexit around it. And we've got a Tory government which is very much moving further to the right and very much moving towards an absolute minimal public sector... and that team that dealt with these difficult to engage groups became absorbed.

The absence of any engagement with organisations in a position to offer support consequently reinforced victims' reluctance to report hate incidents. All too often members of minority communities are described, and sometimes written off as 'hard to reach' by policy makers and practitioners (Spalek, Garland and Chakraborti, 2006) but the process of engagement deployed by the research team in each of our studies enabled us to spend prolonged periods of time with a diverse range of groups within leisure sites and community meeting points across different towns and cities. Far from being 'hard to reach' our research participants were overwhelmingly receptive to the process of engagement and welcomed the opportunity to share experiences and ideas. During interviews many expressed a deep sense of frustration at what they felt were tokenistic approaches to engagement adopted by the police and local authorities, which often took the form of narrow lines of communication with self-styled community leaders who were frequently criticised for being typically male, older and out of touch with the range of 
challenges experienced within their communities. Survey responses in the Leicester Hate Crime Project highlighted that only $1 \%(n=9)$ of respondents had shared their experiences of hate crime with a community leader, and this highlights the inherent dangers of framing policy responses on the basis of such a selective form of engagement. Such an approach also fails to reach beyond fixed and familiar communities, and this was a concern aired repeatedly by participants who did not feel a sense of belonging to an established 'community' but who instead identified, for instance, as being an asylum seeker, homeless, a member of an alternative subculture or as having learning disabilities. For these reasons, many victims called for the police and other relevant organisations to see meaningful community engagement as an integral part of their role and to adopt approaches which generate dialogue with a much more diverse set of voices.

It became evident within each study that the challenges around engagement had become exacerbated by the wider economic climate which had seen many of the more localised support services that work directly with 'hard to reach' groups face closure or significant cuts to resources. This was especially damaging in the context of tailored services for some of the more vulnerable and marginalised groups of hate crime victims who were heavily reliant on such services as a means of accessing support and opportunities for social interaction. The preceding passages have illustrated some of the factors which prevented victims from discussing hate incidents with mainstream organisations but in each study research participants spoke in much more positive terms about smaller, voluntary and community-based services - their mental illhealth support circle, their locally-run women's network, their homeless shelter or their refugee support group, to name just some examples - with whom they felt safe, supported and able to talk openly about their experiences. However, in each area these services had typically been closed down or reduced in size to the point where they lacked the capacity to provide effective support.

Consequently, these closures and cuts to services reinforced many victims' feelings of isolation and reduced the likelihood of them reporting future hate incidents. They also served to stifle some of the more effective channels of communication with minority groups, which in turn makes a mockery of the principles underpinning effective partnership-building with diverse communities which feature so prominently within national and local strategic policy guidance. In the West Midlands and Hertfordshire-based studies 35\% $(\mathrm{n}=39)$ and 19\% $(\mathrm{n}=82)$ of survey respondents, respectively, stated that they had not accessed support following their most recent experience of hate crime because they were not aware of existing support services, and interviews within these and the other studies revealed a worrying lack of familiarity with the term 'hate crime', with the forms of offence that constituted a 'hate crime' and with how to access support. This was particularly acute within smaller and emerging minority communities 
and amongst those from economically disadvantaged environments, and suggests that interventions championed at a national and local level are commonly failing to resonate with some of the most marginalised and vulnerable victims of hate crime. Such victims are typically unable to access support not only because of multiple barriers to reporting or a shortage of services but because they are unaware of the existence of hate crime support services and their status as a hate crime victim.

\section{A failure to deliver meaningful criminal justice interventions}

Preceding sections have referred to improvements made within the domain of criminal justice which include greater consistency in the recording of hate incidents across police forces, the introduction of hate crime legislation across all monitored strands, and the publishing of strategies and guidance notes by criminal justice agencies and partners across England and Wales (Walters and Brown, 2016; CPS, 2016; College of Policing, 2014; Law Commission, 2014). While these are prima facie positive developments, evidence from the present studies shows that they have yet to be fully recognised as such by hate crime victims.

Part of the problem lies in the initial response provided by the criminal justice system, most commonly the police, and how that response is perceived by the victim. Findings from the Crime Survey for England and Wales (CSEW) indicate that victims of hate crime are less satisfied by the response that they receive from criminal justice agencies when compared to other forms of crime, with $52 \%$ of hate crime victims very or fairly satisfied compared with $73 \%$ of victims of non hate offences (Corcoran et al., 2015). The CSEW also shows that hate crime victims are more likely to be very dissatisfied with the police handling of their case than victims of other forms of crime (35\% compared to $14 \%$ ), and this was confirmed within the present studies where the equivalent proportions of survey respondents expressing dissatisfaction were $54 \%(\mathrm{n}=12), 50 \%(\mathrm{n}=23)$ and $35 \%(\mathrm{n}=93)$ in the Hertfordshire- and West Midlands-based studies and the Leicester Hate Crime Project, respectively.

Within each area criticisms of the initial response tended to stem from a feeling of not being listened to, not being taken seriously, and not being treated with an appropriate level of decency and empathy. These problems are deeply concerning given that victims are likely to have already experienced considerable emotional and physical distress as a result of their hate incident and to have negotiated various barriers in order to report the incident. Within the Leicester Hate Crime Project those problems relating to the initial response seemed to be especially acute for those with physical disabilities. The survey findings revealed that only $58 \%$ of respondents $(\mathrm{n}=19)$ who had experienced disablist hate crime believed that the incidents they had reported to the police had even been recorded, while under half $(42 \%$; $=14)$ said that the 
police had investigated the most recent hate incident they had reported. Again, this highlights a disconnect between the stated aims of criminal justice policy to ensure that all reported hate incidents are recorded and investigated (Home Office, 2016; College of Policing, 2014) and the reality as experienced by victims which sees fewer than $50 \%$ of reported hate crimes being recorded as such (Walters and Brown, 2016).

Interviews with victims in each area revealed that problems encountered at the pre-reporting and initial response stages were compounded by what they perceived as a slow, intimidating and at times incomprehensible criminal justice system. Many spoke at length about the difficulties that they had encountered when trying to make sense of what police officers were telling them to do; or the complex, unfamiliar terminology used in reference to hate crime and accompanying legislation; or the seemingly endless delays in waiting to receive any form of communication or follow up; or the hostile manner and tone adopted by frontline practitioners. These criticisms were directed mostly towards the police but also towards other service providers and criminal justice agencies including local authorities, housing associations and the Crown Prosecution Service (CPS), and almost invariably added to the emotional and healthrelated harms incurred from the initial hate incident. The absence of any form of advocacy support in this context was keenly felt across each area by victims whose confidence and capacity to make informed choices about their engagement through the criminal justice process would have been bolstered considerably through the use of independent advocacy workers (see also Brooks and Burman, 2017; Antjoule, 2016).

I went to the police station to report it, and you're sitting there with people that are on the other side of the police station waiting to go into court. And you feel like you're in the naughty chair or something, or you're waiting to see the headteacher ... And then you go into the small room. It was just me, and there were two police officers there ... it's quite an overpowering thing and you're out of your safe zone as well.

Transgender male, aged 20-29

An added frustration for those victims who had reported hate incidents to the police was a perceived failure on the part of criminal justice agencies to bring perpetrators to justice or to even keep them informed on the progress of their case. Within the Leicester Hate Crime Project, for example, only $4 \%(n=39)$ of survey respondents had seen their most recent experience of hate crime go to court. Of those cases that had reached that far, just over half $(54 \%, n=21)$ had seen the offender found guilty, while $5 \%(\mathrm{n}=2)$ had seen the case dismissed or discontinued and a similar proportion had seen a not guilty verdict. CPS (2016) figures reveal a similarly low prosecution rate at a national level, despite the $2015 / 16$ total of 15,442 representing a record 
number of hate crime prosecutions. Indeed, while the overall conviction rate of $83.2 \%$ appears to be high, that figure is based on convictions secured against the numbers of hate crimes prosecuted across all strands, and not the numbers of crimes committed. When we factor in the vast numbers of hate crimes which are not reported by victims, and those which are reported but which are not taken forward for prosecution, it becomes increasingly difficult to draw any meaningful connections between the numbers of prosecutions and the numbers of hate crimes being committed across the country. The difficulties surrounding interpretations of hostility and motive, and the stringent evidential proof required for prosecutions, have been explored elsewhere (Chakraborti and Garland, 2015; Williams and Tregigda, 2013), and these issues can cause added distress to victims, their families and wider communities.

Each research study revealed that many victims were receptive to the extended use of alternative interventions beyond conventional punitive measures. Within the West Midlandsbased research, for example, fewer than half $(44 \% ; n=131)$ of survey respondents referred to longer prison sentences as their preferred response to hate crime. Instead, $82 \%(n=246)$ of survey respondents called for greater use of tailored programmes of education within schools and local communities as a mechanism to inform young people about positive aspects of diversity and the harms of hate crime; $55 \%(\mathrm{n}=167)$ wanted to see more use of community 'payback' orders for hate crime perpetrators; and 32\% $(n=97)$ were in favour of more face to face supervised mediation between the victim and the offender. These feelings were shared amongst victims of different types of violent and non-violent hate crime and from different communities, ages and backgrounds, and illustrate strong levels of support for utilising interventions outside of the formal criminal justice routes within responses to hate crime. However, despite the extended use of such interventions in the context of other criminal offences - and despite a growing body of empirical evidence to support the growth of restorative practices, education programmes and rehabilitative programmes as part of a package of preventative measures to combat hate crimes (Hardy, 2017; Walters and Brown, 2016; Walters, 2014; Hall, 2013) - their use in the context of hate crime remains relatively limited.

Walters and Brown (2016: 21), for instance, refer to the CPS policy against the use of conditional cautions for hate crime and the failure of the recent Government Hate Crime Action Plan (2016) to even mention restorative justice within any of its sections on 'preventing hate crime', 'responding to hate crime in our communities' or 'improving support for victims of hate crime' as evidence of the resistance amongst some statutory agencies to endorse restorative interventions. Equally, although the same Action Plan names a selection of education programmes to evidence its support for early interventions, it is difficult to see how these programmes can deliver sustained success in the context of the myriad of other complex challenges within schools and in the absence of wider investment to take the pressure of 
delivery away from teaching staff who may ill-equipped to engage pupils on issues relating to hate crime. Similar levels of indifference to an increased use of restorative and other interventions were evident within the present research studies, largely because of a lack of interest on the part of local service providers to pilot, resource and evaluate such interventions. Such indifference not only undermines the aims enshrined within national and local strategies, guidance documents and Action Plans to deliver effective hate crime responses; it undermines the importance attached to addressing the needs and expectations of the many thousands of hate crime victims who are failing to receive adequate support from existing criminal justice interventions.

\section{Conclusion}

This article has identified a series of failings within existing policy-level responses to hate crime which undermine their credibility and effectiveness in the eyes of victims. It has drawn from rigorous, in-depth fieldwork to identify a set of specific problems - namely, a failure to dismantle barriers to reporting, a failure to prioritise engagement with diverse communities, and a failure to provide meaningful criminal justice interventions - which affect the capacity of hate crime victims from different identity groups and backgrounds to access appropriate support. Moreover, these problems compound the extensive physical and emotional harms that victims will already have to contend with as part of the process of experiencing hate crime and the sense of alienation that is typically felt within groups who encounter targeted hostility as a routine feature of being 'different'. The risk of secondary victimisation which victims of rape and related offences can encounter as a result of flawed criminal justice processes is well documented (Brooks and Burman, 2017; Brown, 2011; Wykes and Welsh, 2009) and similar challenges are evident in the context of hate crime victims.

Acknowledgement of these problems should not be used to disregard the more positive developments that were referred to earlier. Hate crime has become a burgeoning topic within criminology, and in recent years we have seen the emergence of new ideas which have facilitated some degree of change in cultural attitudes towards the prejudice suffered by a range of minority groups, and wider prioritisation across governments, criminal justice agencies and other service providers. These developments have emerged through the harnessing of stronger links between scholarship and policy which have helped hate crime interventions to transcend, at least in part, the mutual suspicion that often divides the two domains where the value of academic work has often been dismissed by practitioners as high-brow intellectualism with little relevance to the pressures of 'real-world' work, and where the value of working alongside 
practitioners has commonly been overlooked by scholars unwilling to acknowledge the relevance of working outside of their 'ivory towers' (Giannasi, 2014).

Some of the more successful routes to harnessing such links have come through the development of practical toolkits and evidence-based training on hate crime perpetration, prevention and victimisation (Centre for Hate Studies, 2017; ODIHR, 2017; Stop Hate UK, 2017). Typically, they draw from empirical research, policy guidance and, perhaps most importantly, victim testimonies to engage practitioners from different sectors and varying levels of seniority. Establishing channels of communication with different audiences has also been a key priority for groups such as the Sophie Lancaster Foundation, Stonewall, Stop Funding Hate and Tell MAMA whose ongoing campaigns and engagement with policy-makers, criminal justice professionals, academic and a diverse range of public audiences has generated notable success in the context of awareness-raising and improved recording structures (Chakraborti, 2015b; Garland, 2014). Developing partnerships across different spheres of work, utilising victims' voices and making effective use of social media, digital content and other creative outputs has been pivotal for these organisations and others who are seeking to address some of the problems outlined within preceding sections.

However, these endeavours alone are not enough to address the shortcomings identified within this article. In the context of prevailing economic, political and social conditions which act as enabling factors for the continued demonisation of 'marginal' communities, and with levels of hate crime escalating to increasingly alarming levels both within the UK and beyond, using academic evidence to improve existing policy responses becomes all the more important. A number of recent studies have identified feasible, and potentially transformative recommendations which include much more extensive dialogue between criminal justice agencies and diverse communities to generate a wider understanding of hate crime terminology amongst potential and actual victims and appropriate information-sharing structures; a national online hate crime hub to improve the reporting and recording of online incidents; greater use of online apps to make reporting easier for victims and witnesses; more evaluation of existing criminal justice interventions; and more training and consultation with frontline practitioners to generate a shared language, shared policies and a shared understanding of best practice (Hardy and Chakraborti, 2017b; Walters and Brown, 2016; Anjoule, 2016; Chakraborti, Garland and Hardy, 2014)..

Such steps would enable responses to hate crime to move beyond the prevailing shallow, repetitive cycle which sees leading figures simply condemn hate acts as 'utterly unacceptable' and as 'having no place in our society', to coin recent phrases used by the current Home Secretary (Home Office, 2016), and then issuing Action Plans and associated criminal justice strategies to outline actions such as 'looking at' and 'working with' without detailing the 
process through which they will be achieved, monitored and evaluated (see also Walters and Brown, 2016). Without urgent action, hate crime victims will continue to reject opportunities to report their experiences; will become increasingly detached from support structures; and will continue to have little faith in criminal justice responses. This represents the reality of what is already happening all too often and our responses must improve if we are to plug the everwidening chasm between state-level narratives and victims' lived realities.

\section{References}

Antjoule, N. (2016) The Hate Crime Report 2016: Homophobia, Biphobia and Transphobia in the UK, London: Galop.

Awan, I. and Zempi, I. (2017) 'I Will Blow Your Face Off' - Virtual and Physical World AntiMuslim Hate Crime', British Journal of Criminology, 57 (2): 362-380.

BBC News (2017a) 'Record Hate Crimes after EU Referendum, 15 February. Available at http://www.bbc.co.uk/news/amp/38976087

BBC News (2017b) 'Germany hate crime: Nearly 10 attacks a day on migrants in 2016', 26 February. Available at http://www.bbc.co.uk/news/world-europe-39096833

BBC News (2016) 'UN blames UK Politicians for Brexit Hate Crime Spike', 26 August. Available at http://www.bbc.co.uk/news/uk-37193140

Brooks, O. and Burman, M. (2017) 'Reporting Rape: Victim Perspectives on Advocacy Support in the Criminal Justice Process', Criminology and Criminal Justice, 17 (2): 209225.

Brown, J. (2011) 'We Mind and We Care But Have Things Changed? Assessment of Progress in the Reporting, Investigating and Prosecution of Rape', Journal of Sexual Aggression, 17 (3): $263-272$.

Campbell, R. (2014) 'Not Getting Away with It: Linking Sex Work and Hate Crime in Merseyside', in N. Chakraborti and J. Garland (eds) Responding to Hate Crime: The Case for Connecting Policy and Research, Bristol: The Policy Press, pp. 55-70.

Centre for Hate Studies (2017) Training. Available at http://www2.le.ac.uk/departments/criminology/hate/professional

Chakraborti, N. (2015a) 'Re-Thinking Hate Crime: Fresh Challenges for Policy and Practice', Journal of Interpersonal Violence, 30 (10): 1738-1754. 
Chakraborti, N. (2015b) 'Mind the Gap! Making Stronger Connections Between Hate Crime Policy and Scholarship', Criminal Justice Policy Review, 27 (6): 577-589.

Chakraborti, N. and Garland, J. (2015) Hate Crime: Impacts, Causes and Consequences (2nd edn), London: SAGE.

Chakraborti, N. and Hardy, S. (2015) LGB\&T Hate Crime Reporting: Identifying Barriers and Solutions, Manchester: Equality and Human Rights Commission, available at https://www.equalityhumanrights.com/sites/default/files/research-lgbt-hate-crimereporting-identifying-barriers-and-solutions.pdf

Chakraborti, N., Garland, J. and Hardy, S. (2014) The Leicester Hate Crime Project: Findings and Conclusions, Leicester: University of Leicester. Available at http://www2.le.ac.uk/departments/criminology/hate/documents/fc-full-report

Chakraborti, N. and Garland, J. (2012) 'Reconceptualising Hate Crime Victimization through the Lens of Vulnerability and "Difference", Theoretical Criminology, 16 (4), 499-514.

College of Policing (2014) Hate Crime Operational Guidance, Coventry: College of Policing. Corcoran, H., Lader, D. and Smith, K. (2015) 'Hate Crimes, England and Wales, 2014/15', Home Office Statistical Bulletin 05/15. Available at http://www.reportit.org.uk/files/ho hate crime statistics_201415.pdf

Crown Prosecution Service (CPS) (2016) Hate Crime Report 2014-15 and 2015-16. Available at https://www.cps.gov.uk/publications/docs/cps_hate_crime_report_2016.pdf

Dearden, L. (2017) 'Attacks on refugee homes double in Austria as accommodation firebombed and sprayed with Nazi graffiti' in the Independent, 1 April. Available at http://www.independent.co.uk/news/world/europe/refugee-crisis-austria-migrants-asylumseekers-homes-attacks-firebombings-doubles-accomodation-a7661831.html

Garland, J. (2015) 'Conclusions' in N. Chakraborti \& J. Garland (eds.) Responding to Hate Crime: The Case for Connecting Policy and Research, Bristol: The Policy Press, pp. 259268.

Garland, J. Spalek, B. and Chakraborti, N. (2006) 'Hearing Lost Voices: Issues in Researching ‘Hidden’ Minority Ethnic Communities’, British Journal of Criminology, 46 (3): 423-437.

Garland, J. and Hodkinson, P. (2015) 'Alternative Subcultures and Hate Crime', in N. Hall, A. Corb, P. Giannasi and J. Grieve (eds) The Routledge International Handbook of Hate Crime, London: Routledge, pp. 226-36.

Giannasi, P. (2014) 'Academia from a Practitioner's Perspective: A Reflection on the Changes in the Relationship between Academia, Policing and Government in a Hate Crime Context', 
in N. Chakraborti \& J. Garland (eds.) Responding to Hate Crime: The Case for Connecting Policy and Research, Bristol: The Policy Press, pp. 27-38

Hall, N. (2013) Hate Crime (2nd edition), London: Routledge.

Hardy, S. (2017) Everyday Multiculturalism and 'Hidden' Hate, London: Palgrave Macmillan.

Hardy, S. and Chakraborti, N. (2017a) A Postcode Lottery? Mapping Support Services for Hate Crime Victims, Leicester: University of Leicester.

Hardy, S. and Chakraborti, N. (2017b) Hate Crime: Identifying and Dismantling Barriers to Justice. Available at http://www2.le.ac.uk/departments/criminology/hate/research/HateCrimeIdentifyingandDis mantlingBarrierstoJustice.pdf

Hardy, S. and Chakraborti, N. (2016) Healing the Harms: Identifying How Best to Support Hate Crime Victims, available at http://hertscommissioner.org/fluidcms/files/files/pdf/Victims-Commissioning/Healing-theHarms---Final-Report.pdf

Hick, P., Arshad, R., Mitchell, L., Watt, D. and Roberts, L. (2011) Promoting Cohesion, Challenging Expectations: Educating the Teachers of Tomorrow for Race Equality and Diversity in $21^{\text {st }}$ Century Schools, Manchester: Manchester Metropolitan University.

HM Government (2014) Challenge It, Report It, Stop It: Delivering the Government's Hate Crime Action Plan, London: HM Government.

HM Government (2012) Challenge It, Report It, Stop It: The Government's Plan to Tackle Hate Crime, London: HM Government.

Home Office (2016) Action Against Hate: The UK Government's Plan for Tackling Hate Crime, London: Home Office.

Iganski, P. (2001) 'Hate Crimes Hurt More', American Behavioural Scientist, 45 (4): 626-38. Iganski, P. and Lagou, S. (2015) 'The Personal Injuries of 'Hate Crime', in N. Hall, A. Corb, P. Giannasi, and J. Grieve (eds) The Routledge International Handbook on Hate Crime, London: Routledge, pp. 34-46.

Law Commission (2014) Hate Crime: Should the Current Offences Be Extended? Available at https://www.gov.uk/government/uploads/system/uploads/attachment_data/file/316099/978 1474104852 Web.pdf

Mason-Bish, H. (2016) 'Get Yer Tits Out': Why Misogynistic Street Harassment is a Crime. Available at http://www.internationalhatestudies.com/get-yer-tits-out-why-misogynisticstreet-harassment-is-a-hate-crime/ 
Office for Democratic Institutions and Human Rights (ODIHR) (2017) Countering Hate Crime: Working with Civil Society. Available at http://www.osce.org/odihr/counteringhate-crime-working-with-civil-society

Perry, J. (2014) 'Evidencing the Case for Hate Crime', in N. Chakraborti and J. Garland (eds) Responding to Hate Crime: The Case for Connecting Policy and Research, Bristol: The Policy Press, pp. 71-83.

Perry, B. (2001) In the Name of Hate: Understanding Hate Crimes, London: Routledge.

Radford, J. and Stanko, E. (1996) 'Violence against Women and Children: the Contradictions of Crime Control under Patriarchy', in M. Hester, L. Kelly and J. Radford (eds) Women, Violence and Male Power, Buckingham: Open University Press, pp. 65-80.

Southern Poverty Law Centre (2016) The Trump Effect: The Impact of the 2016 Presidential Election on our Nation's Schools. Available at https:/www.splcenter.org/20161128/trumpeffect-impact-2016-presidential-election-our-nations-schools

Spalek, B. (2006) Crime Victims: Theory, Policy and Practice, Basingstoke: Palgrave Macmillan.

Stop Hate UK (2017) Stop Hate UK Training Services. Available at http://www.stophateuk.org/stop-hate-uk-training-services/

Walklate, S. (2007) Imagining the Victim of Crime, Maidenhead: Open University Press.

Walters, M. (2014) Hate Crime and Restorative Justice: Exploring Causes, Repairing Harms, Oxford: Oxford University Press.

Walters, M. and Brown, R. (2016) Preventing Hate Crime: Emerging Practices and Recommendations for the Improved Management of Criminal Justice Interventions, Brighton: University of Sussex.

Williams, M. and Tregidga, J. (2013) All Wales Hate Crime Research Project: Research Overview and Executive Summary, Cardiff: Race Equality First.

Wong, K. and Christmann, K. (2008) 'The Role of Decision-Making in Reporting Hate Crime', Safer Communities, 7 (2): 19-34.

Wykes, M. and Welsh, K. (2009) Violence, Gender and Justice, London: Sage.

\footnotetext{
${ }^{1}$ This work was supported by the Economic and Social Research Council [grant number ES/J008109/1] and by funding awarded by the Equality and Human Rights Commission, and the Offices for the Police and Crime Commissioner in Hertfordshire and in the West Midlands.
} 
2 The term 'victim' is used throughout this article not in a pejorative or patronizing sense but to be consistent with the terminology used within the context of hate crime legislation, policy guidance and research

${ }^{3}$ As the studies were commissioned by different funding bodies with different sets of priorities, budgets and goals, there were variations within the timeframes for each study and the demographics of each sample. Further details about each study, and their individual methodologies, findings and recommendations, can be found in Hardy and Chakraborti, 2017a; 2016; Chakraborti and Hardy, 2015 and Chakraborti, Garland and Hardy, 2014.

${ }^{4}$ The Leicester Hate Crime Project survey was translated into Arabic, Bengali, Gujurati, Mandarin, Polish, Punjabi, Somali and Urdu.

533 research participants in the Hertfordshire-based study completed a questionnaire survey and also took part in an interview.

${ }^{6}$ The descriptions beneath each verbatim extract convey whom each comment is attributed to and use the language deployed by each individual to describe their own identity. The interviewee's name and area of residence has been removed to preserve their anonymity.

${ }^{7}$ The True Vision website (http://www.report-it.org.uk/home) offers information about hate crime and provides a national online reporting facility as an alternative to reporting directly to the police. 